\title{
Profile of the functionaries of KVKs of Assam
}

\author{
MRINMOY CHETIA*, MINERVA SAIKIA BARUAH AND DAISY HAZARIKA \\ Department of Extension and Communication Management, College of Home Science, Assam \\ Agricultural University, JORHAT (ASSAM) INDIA
}

\begin{abstract}
The present study was conducted to know the profile of the KVK functionaries. The study was conducted in $19 \mathrm{KVKs}$ under Assam Agricultural University, which were started functioning on or before 2009. Three different cadres i.e. programme coordinator, subject matter specialist and programme assistant/ farm manager were the respondents for the present study. Data were collected with the help of questionnaire. The findings of the study revealed that educational qualification of the functionaries was high as 100 per cent of the programme coordinators were $\mathrm{Ph} . \mathrm{D}$. and 70.49 per cent subject matter specialists and 58.62 per cent farm managers/ programme assistants are M Sc and large percentage of the functionaries were married. 100 per cent of the programme coordinators were more than 16 years of service experience, while the 29.51 per cent subject matter specialists were having $1-5$ years of experience in service and 44.83 per cent of the programme assistants/ farm managers were experienced of 6-10 years of service. Majority of the respondents were having 1- 5 years of experience in KVK service. Majority of the subject matter specialists and farm manager/ programme assistant were of native of urban areas where as 58.33 per cent of programme coordinators were from rural back ground. Majority of the respondents were from nuclear and small sized family. The KVK functionaries were active in their professional activities. The different activities of professional life show different level of activeness. Though the functionaries were more active with professional society prior to join KVK but their activeness is decreasing after joining KVK. After joining KVK the percentage of attending seminar or conferences were decreasing fro programme coordinator and subject matter specialists, but for the programme assistant/ farm managers the attending percentage were increasing.
\end{abstract}

Key Words : KVK, Functionaries, Profile, Training/ professional achievement

View Point Article : Chetia, Mrinmoy, Baruah, Minerva Saikia and Hazarika, Daisy (2014). Profile of the functionaries of KVKs of Assam. Internat. J. Home. Sci. Extn. \& Comm. Mgmt., 1 (2): 111-114.

Article History : Received : 08.02.2014; Revised : 03.06.2014; Accepted : 15.06.2014

\footnotetext{
* Author for correspondence
} 